\title{
WEARABLE TECHNOLOGY: OPPORTUNITIES AND CHALLENGES FOR TEACHING AND LEARNING IN HIGHER EDUCATION IN DEVELOPING COUNTRIES
}

\author{
Azubuike Ezenwoke, Omotola Ezenwoke, Adewole Adewumi, Nicholas \\ Omoregbe
}

\author{
Covenant University (NIGERIA)
}

\begin{abstract}
The higher education landscape in developing countries is faced with many challenges, one of which is high faculty to student ratio. An obvious implication of this is compromise on the quality of classroom engagement. The distractions caused by the not conducive learning space and instructors' inability to elucidate correct feedbacks from students usually lead to poor learning outcomes. Feedback mechanisms that are unobtrusive and efficient in processing large data in real-time are needful to measure quality learning experience in such large classroom settings. With the latest impact of penetration and adoption of internet and mobile technologies in most developing counties, wearable technology is a feasible solution to manage and monitor classroom involvement; as real time student feedback can be integrated in the design and delivery of instruction in and out of the classroom. In this paper, we present state of the art of wearable technology and explored the opportunities of wearable technology in the higher education. Specifically, we presented scenarios in which wearable technology can be employed to understand and analyze physiological signals and emotional responses from learners in real-time; the end result of which would increase the quality of classroom engagement, inspire new pedagogy, drive new trends in peer-to-peer collaborations, and increase the learning outcomes. Moreover, we identified some challenges that may hinder this development such as: inconclusive user studies of wearable technology in developing countries and inadequate infrastructure. Finally, we make appropriate recommendations on how these challenges can be surmounted
\end{abstract}

Keywords: Wearable technology, education, Google glass, XOX.

\section{INTRODUCTION}

The regulatory body for higher education in many developing countries is charged with the responsibility of improving the quality of education in the university system, and pivotal is the maintenance of minimum academic standards [1;2]. Maintaining minimum standards with increasing enrolment rates are inundated with some challenges including, inadequate funding, large class sizes and high student-faculty ratio; and these are important dimensions in academic delivery [3]. An obvious implication of these challenges is the compromise on the quality of classroom engagement, as the primary learning needs of the students are often neglected. The distractions caused by the not conducive learning space and instructors' inability to elucidate correct feedbacks from students usually lead to poor learning outcomes [4]. To improve on learning outcomes, it is desirable that instructors possess the capacity to monitor student classroom engagement, with the aim of identifying and responding efficiently to student's needs. Such responsiveness increases student interest [5], and situates the importance of the human factor in teaching, while also confirming that student's interest can be triggered by students' perception of the instructor's attention to them [6]. Although monitoring classroom engagement consists of three dimensions: cognitive, behavioural and affective (emotional), recognizing and measuring emotional phenomena (such as interest, boredom, or surprise) play a vital role in providing appropriate instructor-led intervention and increases the responsiveness of instructors [7]. The resultants effect of which is a classroom ambience that fosters empathy and enhance learning [8; 9], and assures students' motivation in the long run [10]. However, coordinating effective instructorstudent interaction in large classroom settings is nontrivial, as feedback mechanisms that are unobtrusive and efficient in processing large emotional data in real-time are needful [11], which could be employed to measure quality learning experience in such large classroom settings.

With the latest impact of penetration and adoption of internet and mobile technologies in most developing counties, wearable technology is a feasible solution to manage and monitor classroom involvement within large classroom settings; as real time student feedback can be integrated in the 
design and delivery of instruction in and out of the classroom. In this paper, we present state of the art of wearable technology and explored the opportunities of wearable technology in the higher education. Specifically, we presented scenarios in which wearable technology can be employed to understand and analyse physiological signals and emotional responses from learners in real-time; the end result of which would increase the quality of classroom engagement, inspire new pedagogy, drive new trends in peer-to-peer collaborations, and increase the learning outcomes. The Rest of the Paper is structured as follows: Section 2 discusses monitoring student classroom engagement and the role of technology in this process, with emphasis on the potentials of wearable technology. The scenarios for employing emotion-aware wearable technology to monitor classroom engagement in large are presented in section 3; while the opportunities and challenges for adopting of wearable technology is discussed in section 4 . This paper concludes in section 5 .

\section{BACKGROUND}

\subsection{Student Classroom Engagement and Monitoring}

Student classroom engagement can be defined as student's active involvement in learning activities in the classroom environment [12;13], and the extent of attention, curiosity, interest, optimism, and passion that student exhibit during learning activities [14; 15]. Indeed improved participation in the classroom usually leads to improved motivation and performance in a course or subject [16], however surprising is that most students are increasingly under-engaged or dis-engaged in many classroom settings [17, p. 18]; and authentic learning will only happen to the extent of engagement during the learning process. Generally, student classroom engagement is characterized by the cognitive, behavioural and affective (or emotional) dimensions exhibited by students in the classroom context [18], and how they impact on overall academic performance. Behavioural engagement describes observable conducts such as time-on task, classroom participation, and question asking; while cognitive engagement refers to mental effort, such as, concentration and metacognition [19]. Affective (emotional) engagement refers to positive emotions during learning activities in the classroom (e.g. interest, curiosity, enjoyment, and enthusiasm) [18; 13], and such emotional phenomena are important dimensions that provide useful feedback in measuring the quality of student engagement in the classroom [20; 21].

Classroom monitoring is the means by which instructors keep track of students' involvement in the learning process in order to improve pedagogical decisions [22]. Traditional monitoring techniques include, among others: self-reporting, checklists and rating scales, and direct observations [23]. In self-reporting, the information volunteered by the students through surveys or questionnaires are used to measure student engagement; while the instructor employs rating scales to measure student engagement levels in checklists and rating scale methods. In direct observation, instructors directly observe students during lecture session and make recommendations for appropriate intervention. Although, direct observation is expected to make-up for the concerns on the validity of the subjective information provided by students themselves in self-reporting [24], direct observation also suffers from the instructor's subjective opinion, while itself been cumbersome and time-consuming. Manually eliciting these feedbacks can be tedious and subjective in nature and as such instant and actionable feedbacks on affective, cognitive and behavioral cues enabled by the use of technology can better enrich student experience while driving engagement. The use of relatively unobtrusive forms of classroom monitoring technologies to harvest, and analysis student feedbacks would lead to more informed decisions about improving teaching and learning.

\subsection{Technology-enabled Classroom Monitoring}

Technology has irremediably brought changes to varied aspects of human life. The effect of this is evidence in the new ways we communicate, share experiences, buy, sell, and also teach and learn. The advent of the internet and miniaturized computing devices such as PCs, Tablets, mobile phones and other portable and wearable devices has contributed to the popularity and wide adoption of technology-assisted learning paradigms such as e-learning, m-learning, game-based learning etc. These platforms have become progressively necessary in the learning environment, a wide range of geographically dispersed audience of learners can be reached in at a reduced cost via e-learning platforms [25]; learning can take place anywhere and anytime with m-learning [26]; and apart from delivering education, game-based learning also improve the problem solving skills of learners [27]. In the light of these advancements, portable and wearable technologies open a new vista to infinite 
opportunities for transformational and massive changes in the way education is being delivered and received [28; 29; 30; 31; 32].

For example, portable student response systems (also referred to as classroom response system, audience response technology, electronic voting system or simply, clickers) have been widely applied in order to elicit responses from student on cognitive tasks during classroom sessions, with some measure of success [33; 34]. Clickers incorporate a wireless system that enables the instructor post a multiple choice questions during a lecture and each student respond by selecting a preferred option using handset devices (clickers). The handsets transmit the answers to a receiver for the voting software to aggregate the responses; the aggregated responses is summarized into a pictorial chart and the results are displayed to the entire class [34]. clickers enables a question-driven model of instruction, and indeed, a viable means to monitor student's cognitive commitment to the lecture, measure understanding, reveal and correct some misconceptions [35; 36; 37]. However, the clicker technology necessitates that the students themselves respond by clicking [32], and they do not measure the emotional (or affective) underpinnings that also underscores classroom engagement [38; 20; 21]. Extending the success of the clicker technology would be to include the use of unobtrusive affect-sensitive wearable sensor technology that can elicit biofeedback from the students indirectly.

\subsection{Wearable Technologies and Classroom Monitoring}

Generally, wearable technology are devices that contain a microprocessor, are able to run user defined software applications and are worn on a user's body to allow for non-invasive bio-monitoring functionality and possibly provide a hands-free computing experience [18; 39; 40; 31]. Wearable technologies is different from mobile technologies in that wearable devices can be available at all times, unlike smart phones are handheld, in a pocket or a bag. Wearable technology can be grouped into: wrist-worn wearable and Optical Head Mounted Display (OHMD). OHMD devices are usually worn on the head and/or over the eye. While some are designed to completely immerse the wearer in augmented virtual reality (e.g. Oculus Rift [41]); others such as the Google Glass [21] and Microsoft HoloLens [42] act as an overlay of information thus allowing a user to see through them and still maintain contact with the physical world. Google glass (or simply GLASS) is comprise a bone conduction transducer to transmit audio; a microphone that enables phone and video calls, text dictation for e-mail, messages, and notes; a camera, and several sensors like gyroscope, accelerometer, and GPS; Wi-Fi and Bluetooth connectivity; storage; and a see-through display called prism. In all GLASS can be used to gather personal information during daily activities [21]. Wrist-worn wearable devices include smart watches and fitness bands. Smart watches (e.g. Apple watch [43] and Samsung gear watch [44]) are worn on the wrist and can connect to a mobile phone to act as miniwindows to exploring wearer's digital life. Fitness bands (e.g. Microsoft band [45]) on the other hand help to track the fitness of their user by monitoring heart and pulse rate. Fitness bands can also connect to a cloud platform to give accurate health-related recommendations to the user based on the data gathered.

Some recent advances in wearable sensor technology have made it possible to monitor affective state of wearers in real-time by reading user's psychological signals [46]. These technologies are collectively referred to as affective computing [47]. Affect-sensitive devices are fitted with sensors to read some type of physiological signal, then, pattern recognition tools are employed to recognize physiological aspects of emotion, and to deduce the likely emotional states [47; $21 ; 48]$. The inputs to these sensors include: face, voice, hand gestures, posture and gait, respiration, electro-dermal response (or electro-dermal activity), temperature, electrocardiogram, galvanic skin response, blood pressure, blood volume pulse, facial electromyogram, etc. [47]. For example, MoodWings [46] is a butterfly shaped wearable technology, used to reflect a wearer's stress state in real-time, through stimulated wing motions. The butterfly responds to users' arousal stress states via wings actuation, in which a high stress arousal triggers a large flap, and vice versa. Affectiva [49] is a commercial wearable sensor that recognizes emotions by measuring electro-dermal activity, surface temperature and acceleration. Other wrist-worn wearable such as XOX sensory wrist-band [50] allows for real-time collection, analysis and biofeedback of emotional data from large audience. The use of affect-sensitive wearables is increasing in a number of domains [39], including gaming [51], health [30; 52], rehabilitation [53], and education [54].

In education, such affect-sensitive wearables can unobtrusively allow instructors monitor the emotional state of the students, in order to adopt possible combination of instructional strategies that would arouse the emotional state that is conducive to learning in large classroom settings. For example, instructors can be alerted to devise means to help students maintain focus on the lesson when they 
get distracted, or know when to break the monotony of the class by introducing physical activities that can further enrich the learning process. We presented two use case scenarios in which Optical head mounted display (OHMD), and sensory wrist-bands can be employed to understand and analyze physiological signals and emotional responses from learners in real-time in introductory undergraduate course in Accounting. This case study is based on the teaching scenario from a university in Nigeria.

\section{SCENARIO}

Introduction to Accounting (ACC111) is an introductory Accounting course designed for freshmen in which students are exposed to the rudiment of accounting and requires that students gets the basic knowledge of Bookkeeping and Accounting. A minimum of 3 contact hours each week for 12 weeks is expected. Some specific learning objectives of the course includes: understanding of basic bookkeeping and accounting definitions, terms and terminologies; having good grasp of capital revenues and expense classifications; have an insight into accounting standards; identify errors in accounts and how to correct such errors; and, attempt to draw a final accounts. About 700 students are usually registered for this course, which is usually team-taught. The registered students comprise students from 6 other undergraduate programmes in the university, including Economics, Business administration, Banking and finance, Marketing, Estate management, and Management Information System. The group is broken down into six classes, with a team of instructors for each group and an average class size of 120 students, and each classroom is fitted with a smart-board and Wi-Fi connection. In this scenario, monitoring 120 students' engagement during teaching session is nontrivial and necessitates the use of unobtrusive feedback mechanisms to ensure quality learning experience in such large classroom settings.

\subsection{Classroom Monitoring with Optical Head Mounted Display}

Teaching with an Optical Head Mounted Display (OHMD), the instructor can monitor the facial gesture of the student as he/she moves round the classroom in the course of delivering the lesson. The audience of learners would possess a variety of affective states in the course of the lecture, and the instructor can intelligently recognize the emotional states of the students by collectively analyzing the facial gestures en masse. This information can be visualized through the OHMD's see-through display for the instructor to respond accordingly. This way, the instructor can learn what aspect of the lesson triggers certain responses and in what context, and adjust instructional approaches as required. The camera feature on the OHMD can pick facial gestures from the classroom, send this signals to a remote server and analyze the physiologically signals to produce an aggregated emotional metric. The aggregated emotional metric could be a measure of the intensity of curiosity, interest and surprise as against boredom or stress from students' facial cues. The instructor can continuously adapt his/her behaviour to in response to these feedbacks and can introduce activities that ensure students are sufficiently engagement. Based on some recent development, Google glass can be employed to recognize, measure, and adapt emotions in such a classroom settings [21]. For example, connecting GLASS with $Q^{T M}$ sensor from Affective [49] allows a continuous measurement, analysis and visualization of the stream of data captured via the camera [21], and the feedback is send to the wearer via Bluetooth. Affectiva $Q^{\mathrm{TM}}$ Sensor is used to capture sympathetic nervous system activation, such as heart rate variability and facial expressions [49]. Since GLASS is worn over the eyes, the instructor can unobtrusively visualize real-time emotional data, and immediately see the impact of adapting his/her behaviour on emotional states of the students [21].

\subsection{Monitoring with Wrist-Worn Emotional Sensory Wristband}

Unlike the use of OHMD in which the instructor wears the affect-sensitive device, another possibility is the students wearing sensory wristbands that are capable of collecting and interpreting electrical characteristics of the wearer's skin in order to understand the emotional state of the wearer. The information containing the processed collective emotional states of the students accessed via a smartphone or displayed on a screen, can be used by the instructor to pinpoint which students are having some difficulties with certain aspect of the lecture, or measure the level of students' attention [29]. A potential technology for achieving this is XOX [50]. XOX comprises of the XOX sensory wristbands fitted with biometric sensors that collect physiological data, through the XOX base, transmits and receive signals from XOX servers, where the physiological data is processed to interpret underlying emotional states. The latest version of XOX is fitted with RGB LED that indicates various arousal states. Instructors can use this color-coded biofeedback to identify specific cases needing attention in the classroom. XOX technologies has been tested at events involving large audiences, 
where the audience's emotional feedback is elicited and used to allow them co-create the experience in the course of the event [50].

In the use cases just described, the data collected using both the OHDM and sensory wristbands can be stored and used to perform posterior analysis of the overall learning experience in the classroom for the entire duration of the course in a semester(s). Furthermore, sharing the real-time feedbacks with the students could also help students understand their own physiological states and its impact on their learning behaviour. This would provide a platform for students and instructors to work together in enhancing the quality of teaching and learning in the classroom. The end result of which would increase the quality of classroom engagement; inspire new pedagogy; drive new trends in peer-topeer collaborations; and increase the learning outcomes.

\section{OPPORTUNITIES AND CHALLENGES OF DEVELOPING COUNTRIES}

The University system forms a significant part of higher education. For example, higher education (HE) landscape in Nigeria is defined by four categories of tertiary institutions, and comprises 141 Universities, 95 Polytechnics, 27 monotechnics and 83 colleges of education. Being the highest form of tertiary education, the Universities in Nigeria records high subscription and admission rate of students and majority of these students can be classified as Generation Y. A key characteristic of this group is their affinity for cutting-edge technology, such as the internet, mobile technologies, online social media etc. Indeed, taking a cue from the significant growth in the use of internet and mobile technologies in developing countries, the adoption of wearable technology is predicted to increase. According to [55] the statistics of individual using internet in the developing countries is put at $39.1 \%$ while that of mobile broadband subscriber is at $35.3 \%$. These statistics is a potential basis to forecast that the adoption of wearable technology in developing countries will bourgeon. This is particularly so for countries already investing in backbone services that supports mobile technologies and smartphone devices. For example, m-learning is gaining popularity in developing countries, as about $24 \%$ of persons in developing countries habitually use mobile internet for educational purposes in 2014 [56]. As this backbone is strengthened, the market would become more fertile for mass-adoption of mobile technologies, which will impact on the wearable technology market [57], and also its application in educational activities.

However, some factors ought to be put in consideration if the wearable revolution is to realize its potential for use in higher education in developing countries. We have identified two issues that need addressing, which are the need for more inclusive user studies, and infrastructure development. Apart from the potential for student distraction in the classroom [58], the advent of wearable technologies raises a lot of issues relating to the feasibility of its use, particularly in education. There is need for more inclusive user studies that borders on issues relating to adoption based on privacy concerns. The capability of wearable technologies to instantaneously transmit and receive personal data raises a privacy, social and ethical concerns [31; 46], particularly relating to socio-cultural milieu in most developing countries. In addition, ICT infrastructural development in the area of widespread and uninterrupted internet network and connectivity infrastructure must be addressed to support the use of these technologies in the classroom environment.

\section{CONCLUSION}

Technology-mediated means that enable instructors elicit feedbacks from students and to respond to these feedbacks is a way to cultivate rich classroom interactions that is conducive for teaching and learning. Apart from measuring cognitive engagements, determining the enjoy-ability of the learning process is also important in promoting sustained motivation in the students over the long-term. Noting that large overcrowded classrooms are commonplace in many higher institutions of learning, particularly in developing countries, we presented application scenarios in which wearable technology can foster student classroom engagement in such settings using Optical Head Mounted display and sensory wrist-band technologies. This paper demonstrates the potential of the wearable technology in large class sizes and we believe that potentially, wearable technology can revolutionize higher education landscape in developing countries. However, inclusive users' acceptance studies and provision of adequate infrastructure are some of the requirements in realizing these potentials, and therefore call for more research activities in this domain, as it pertains to developing countries. 


\section{REFERENCES}

[1] Venkatesh, P. (2013). Accreditation as a Benchmark of Quality Sustenance in Higher Education: A Review of Quality Assurance in Indian University System. Nitte Management Review , 59-67.

[2] Hayward, F. M. (2006). Quality assurance and accreditation of higher education in Africa. Conference on Higher Education Reform in Francophone Africa: Understanding the Keys of Success, (pp. 1-61).

[3] Khanna, M., Jacob, I., \& Yadav, N. (2014). Identifying and analyzing touchpoints for building a higher education brand. Journal of Marketing for Higher Education , 122-143.

[4] Chen, R. (2012). Institutional characteristics and college student dropout risks: A multilevel event history analysis. Research in Higher Education , 487-505.

[5] Abrantes, J. L., Seabra, C., \& Lages, L. F. (2007). Pedagogical affect, student interest, and learning performance. Journal of Business Research , 960--964.

[6] Paswan, A. K., \& Young, J. A. (2002). Student evaluation of instructor: A nomological investigation using structural equation modeling. Journal of Marketing Education , 193-202.

[7] Arroyo, I., Cooper, D. G., Burleson, W., Woolf, B. P., Muldner, K., \& Christopherson, R. (2009). Emotion Sensors Go To School. AlED, 17-24.

[8] Zimmerman, B. J. (2000). Self-efficacy: An essential motive to learn. Contemporary educational psychology , 82-91.

[9] Graham, S., \& Weiner, B. (1996). Theories and principles of motivation. Handbook of educational psychology , 63-84.

[10] Wentzel, K., \& Asher, S. R. (1995). The academic lives of neglected, rejected, popular, and controversial children. Child development , 754-763.

[11] Whitehouse, B., \& He, S. (2015). Designing for Humans in a Digital Age: Building Wearable Technology to Convey Information and Emotions\}. Proceedings of the Ninth International Conference on Tangible, Embedded, and Embodied Interaction (pp. 501--504). ACM.

[12] Reeve, J., Jang, H., Carrell, D., Jeon, S., \& Barch, J. (2004). Enhancing students' engagement by increasing teachers' autonomy support. Motivation and emotion , 147-169.

[13] Skinner, E. A., Kindermann, T. A., \& Furrer, C. J. (2008). A motivational perspective on engagement and disaffection: Conceptualization and assessment of children's behavioral and emotional participation in academic activities in the classroom. Educational and Psychological Measurement.

[14] Kuh, G. D. (2007). How to help students achieve. Chronicle of Higher Education , B12-13.

[15] Trowler, V. (2010). Student engagement literature review. York: Higher Education Academy.

[16] Keegan, B., \& Schoen-Phelan, B. (2015). Monitoring Student Engagement and Improving Performance. ICE2015. Dublin: Dublin Institute of Technology.

[17] Schmoker, M. (2006). Results now: How we can achieve unprecedented improvements in teaching and learning. ASCD.

[18] Fredricks, J. A., Blumenfeld, P. C., \& Paris, A. H. (2004). School engagement: Potential of the concept, state of the evidence. Review of educational research , 59-109.

[19] Wang, Z., Bergin, C., \& Bergin, D. A. (2014). Measuring engagement in fourth to twelfth grade classrooms: The Classroom Engagement Inventory. School Psychology Quarterly , 517.

[20] Meyer, D. K., \& Turner, J. C. (2006). Re-conceptualizing emotion and motivation to learn in classroom contexts. Educational Psychology Review , 377-390.

[21] Hernandez, J., \& Picard, R. W. (2014). SenseGlass: Using Google Glass to sense daily emotions. Proceedings of the adjunct publication of the 27th annual ACM symposium on User interface software and technology (pp. 77--78). ACM. 
[22] Cotton, K. (1988). Monitoring student learning in the classroom. Northwest Regional Educational Laboratory.

[23] Chapman, E. (2003). Alternative approaches to assessing student engagement rates. Practical assessment, research and evaluation .

[24] Assor, A., \& Connell, J. P. (1992). The validity of students' self-reports as measures of performance affecting self-appraisals. Student perceptions in the classroom , 25-47.

[25] Charrondiere, U. R., Nowak, V., Nicodemi, C., Bruggeling, P., \& Petracchi, C. (2016). FAO/INFOODS e-Learning Course on Food Composition Data. Food Chemistry , 6-11.

[26] Althunibat, A. (2015). Determining the factors influencing students' intention to use m-learning in Jordan higher education. Computers in Human Behavior, 65-71.

[27] Sukran Ucus, S. (2014). Elementary School Teachers' Views on Game-based Learning as a Teaching Method. 5th World Conference on Learning, Teaching and Educational Leadership, WCLTA 2014, (pp. 401-409).

[28] Fichten, C. S., Asuncion, J., \& Scapin, R. (2014). Digital Technology, Learning, and Postsecondary Students with Disabilities: Where We've Been and Where We're Going. Journal of Postsecondary Education and Disability , 369-379.

[29] Nakamura, C. G. (2015). How wearable computingcomputing can help young children with ADHD to learn.

[30] Vallurupalli, S., Paydak, H., Agarwal, S., Agrawal, M., \& Assad-Kottner, C. (2013). Wearable technology to improve education and patient outcomes in a cardiology fellowship program-a feasibility study. Health and Technology, 267-270.

[31] Bower, M. a. (2015). What are the educational affordances of wearable technologies? Computers \& Education , 343-353.

[32] Hunsu, N. J., Adesope, O., \& Bayly, D. J. (2016). A meta-analysis of the effects of audience response systems (clicker-based technologies) on cognition and affect. Computers \& Education , 102-119.

[33] Sprague, E. W., \& Dahl, D. W. (2009). Learning to click: An evaluation of the personal response system clicker technology in introductory marketing courses. Journal of Marketing Education.

[34] Deal, A. (2007, Novemner 30). Classroom Response Systems, A Teaching with Technology White Paper. Retrieved January 12, 2016, from Office of Technology for Education, Carnegie Mellon University: http://www.cmu.edu/teaching/technology/whitepapers/ClassroomResponse_Nov07.pdf

[35] Caldwell, J. (2007). Clickers in the large classroom: Current research and best-practice tips. CBE-Life Sciences Education, 9-20.

[36] Lin, Y.-C., Liu, T.-C., \& Chu, C.-C. (2011). Implementing clickers to assist learning in science lectures: The Clicker-Assisted Conceptual Change model. Australasian Journal of Educational Technology , 979-996.

[37] Gok, T. (2011). An Evaluation of Student Response Systems from the Viewpoint of Instructors and Students.\}. Turkish Online Journal of Educational Technology-TOJET , 67-83.

[38] Brosch, T., Scherer, K. R., Grandjean, D., \& Sander, D. (2013). The impact of emotion on perception, attention, memory, and decision-making. Swiss Med. Wkly, w13786.

[39] Tehrani, K., \& Michael, A. (2014). Wearable Technology and Wearable Devices: Everything You Need to Know. Wearable Devices Magazine.

[40] Barfield, W., \& Caudell, T. (2001). Basic concepts in wearable computers and augmented reality. Fundamentals of wearable computers and augmented reality, 3-26.

[41] Oculus. (2016). Oculus Rift. Retrieved from https://www.oculus.com/en-us/

[42] Microsoft. (2016). Microsoft Hololens. Retrieved from https://www.microsoft.com/microsofthololens/en-us

[43] Apple. (2015). Apple Watch. Retrieved from http://www.apple.com/watch/ 
[44] Samsung. (2015). Samsung Gear S2. Retrieved from http://www.samsung.com/us/explore/gear-s2/

[45] Microsoft. (2015). Microsoft Band . Retrieved from https://www.microsoft.com/microsoftband/en-us

[46] MacLean, D. a. (2013). MoodWings: a wearable biofeedback device for real-time stress intervention. Proceedings of the 6th International Conference on Pervasive Technologies Related to Assistive Environments (p. 66). ACM.

[47] Picard, R. (1997). Affective computing. Cambridge: MIT press.

[48] Calvo, R., \& D'Mello, S. (2010). Affect detection: An interdisciplinary review of models, methods, and their applications. IEEE Transactions on Affective Computing, 18-37.

[49] Picard, R. W. (2011). Measuring affect in the wild. Affective Computing and Intelligent Interaction , 3-3.

[50] XOX. (2015). XOX. Retrieved from XOVIA Website: http://www.xoxemotionaltech.com/

[51] Tanenbaum, J., Tanenbaum, K., Isbister, K., Abe, K., Sullivan, A., \& Anzivino, L. (2015). Costumes and Wearables as Game Controllers. Proceedings of the Ninth International Conference on Tangible, Embedded, and Embodied Interaction (pp. 477-480). ACM.

[52] Hashimoto, D. A., Phitayakorn, R., Fernandez-del Castillo, C., \& Meireles, O. (2015). A blinded assessment of video quality in wearable technology for telementoring in open surgery: the Google Glass experience. Surgical endoscopy, 1-7.

[53] Patel, S., Park, H., Bonato, P., Chan, L., \& Rodgers, M. (2012). A review of wearable sensors and systems with application in rehabilitation. J Neuroeng Rehabil, 1-17.

[54] Devine, T., Gormley, C., \& Doyle, P. (2015). Lights, Camera, Action: Using Wearable Camera and Interactive Video Technologies for the Teaching I\& Assessment of Lab Experiments. International Journal of Innovation in Science and Mathematics Education.

[55] ITU and UNESCO. (2015, September). The state of broadband 2015: Broadband as a foundation for sustainable development- a report by the broadband commission for digital development. Retrieved January 16, 2016, from Broad Band Commision for sustainable development website: http://www.broadbandcommission.org/documents/reports/bbannualreport2015.pdf

[56] Internet Society. (2015). INTERNET SOCIETY GLOBAL INTERNET REPORT 2015 MOBILE EVOLUTION AND DEVELOPMENT OF THE INTERNET. Retrieved January 12, 2016, from Internet Society Website:

http://www.internetsociety.org/globalinternetreport/assets/download/IS_web.pdf

[57] Veremis, M. (2015, March 5). Why developing markets are ripe for wearable technology. Retrieved January 12, 2016, from http://www.wearabletechnologynews.com/news/2015/mar/05/why-developing-markets-are-ripe-wearable-technology/

[58] Coffman, T., \& Klinger, M. B. (2015). Google Glass: Using Wearable Technologies to Enhance Teaching and Learning. Society for Information Technology \& Teacher Education International Conference, (pp. 1777-1780). 